\title{
Estimation of in situ stress from borehole breakout for improved understanding of excavation overbreak in brittle-anisotropic rock
}

\author{
A LeRiche Queen's University, Canada \\ KS Kalenchuk Mine Design Engineering, Canada \\ MS Diederichs Queen's University, Canada
}

\begin{abstract}
During deep tunnelling or mining infrastructure development, the assumed stress state has significant implications on geomechanical design. Remote measurement of the three-dimensional stress state at depth has proven to be a significant challenge and is often assumed from historic tests or the regional tectonic setting. To date, borehole breakout analysis has only provided some assistance for orientation of the principal stresses in the plane perpendicular to the borehole axis. This paper presents a stress estimation methodology using numerical modelling, which allows for the back analysis of breakout profiles from a shaft pilot hole at KGHM's Victoria project in Sudbury, Canada. By iteratively changing the horizontal principal stress ratio and maximum tangential wall stress, a set of generalised curves relating breakout characteristics (breakout depth and opening angle) and borehole strength along the $2 \mathrm{~km}$ borehole were made. By recording the change in breakout geometry along the length of the hole, the curves can be used to gain an understanding of changes in stress state as a function of depth and lithology. Given the foliated nature of the units intersected throughout the borehole, the effects of systematically oriented structure on breakout was assessed. This provides a relative understanding of how such structure may cause an overestimation of stress from the back analysis of breakout. With the choice of an appropriate constitutive model, characterisation of the full stress tensor through back analysis of borehole scale failure was made with a greater degree of confidence.
\end{abstract}

Keywords: borehole breakout, effective borehole strength, in situ stress, acoustic televiewer (ATV), excavation overbreak, brittle rock mass modelling

\section{Introduction}

As mining continues to develop deeper and more technically demanding deposits, properly characterising the state of stress has an increasingly important role. In such high risk settings, understanding the potential magnitude of overbreak or ore dilution has repercussions on an entire mine's life, from feasibility studies and mine design to closure and rehabilitation. A preliminary assessment of stress can be done through the review of borehole breakout, which is measured by devices such as an acoustic televiewer (ATV). This is convenient in many cases as it uses existing boreholes and can be done across an entire deposit to greatly increase the spatial resolution of stress.

During the creation of one of the most comprehensive world stress databases, it was found at this time that $28 \%$ of all stress characterisation studies were completed using borehole breakout (Zoback 1992). Since then, significant work has been done to understand the mechanisms behind breakout to refine these results. As confidence in this methodology increases, so too does the ability to incorporate greater levels of detail in the form of geological variability and how it may influence breakout. This could include the presence of micro-structure such as foliation or stiffness contrasts between distinct lithologies. All of this is with the idea that properly developing the local stress tensor can be extrapolated into the prediction of excavation scale failure and ways to manage this during development. 


\section{$1.1 \quad$ Review of breakout mechanics}

\subsubsection{Stress around a borehole}

At any location within the earth's upper lithosphere, the stress state is the sum of the regional forces acting at that location. This is largely dominated by overburden pressure and the tectonic evolution of the area (first-order) but also sees local changes in magnitude and orientation from second-order features (Zoback 1992). In a passive, mid-continental setting such as Sudbury, these local variations in stress can be a result of crustal isostatic rebound from glacial melting, or contrasts in material properties in both a lateral and vertical sense.

The condition of stress surrounding a borehole caused by these first- and second-order forces is highly dependent on the mechanical properties of the surrounding rock. These properties can significantly vary based on the presence of features such as jointing, veining or micro defects at the grain size scale. As a first pass analysis, the stress in the vicinity of a borehole in a perfectly elastic and isotropic medium can be estimated using the well-known Kirsch solution. From this it can be deduced that the location of maximum tangential wall stress around an infinitely long borehole is located at $90^{\circ}$ to the maximum in-plane stress direction (Kirsch 1898). Based on this elastic theory of stress distribution, initial work was done by Barton et al. (1988); Vernik and Zoback (1992); and Zoback et al. (1985), to estimate in situ stress from the geometry of breakout. As shown in Figure 1, breakout is characterised based on its radial depth and angular extent (opening angle). Of all the work done, the simplest approach was taken by Barton et al. (1988), who estimated the maximum principal stress in a vertical borehole with the following equation:

$$
\sigma_{H}=\frac{C_{o}+\Delta P_{w}+2 P_{p}}{1-2 \cos (2 \theta)}-\sigma_{h} \frac{1+2 \cos (2 \theta)}{1-2 \cos (2 \theta)}
$$

where:
$\sigma_{H} \quad=$ maximum in situ horizontal stress.
$\sigma_{h} \quad=$ minimum in situ horizontal stress.
$C_{0}=$ borehole wall strength (BWS).
$\Theta \quad=$ angle measured between $\sigma_{H}$ and the edge of breakout.
$P_{p} \quad=$ rock pore pressure.
$\Delta P_{w}=$ fluid pressure difference between borehole fluid pressure and pore pressure.

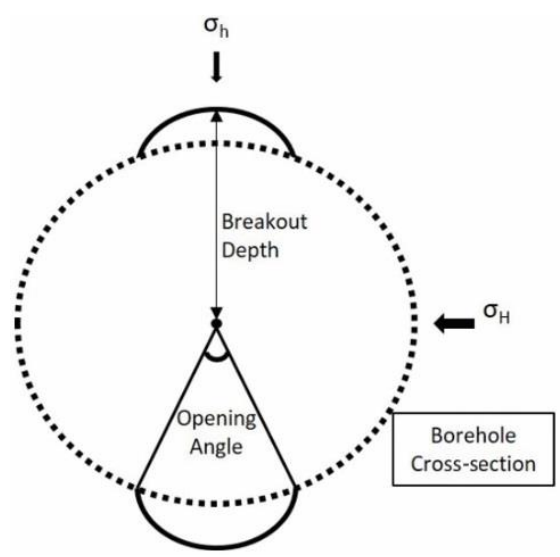

Figure 1 Characteristics of borehole breakout with stress shown for a vertically oriented hole

From Equation (1), it can be seen that these first methods of stress estimation were based on some prior knowledge of the stress state. In the case of the work by Barton et al. (1988), this required an assumption to be made about the magnitude of $\sigma_{h}$. If possible, this was done by using an estimated horizontal principal stress ratio $\left(K_{x y}\right)$ from a regional stress database or by completing a costly and sometimes inconclusive hydraulic fracturing test. This method also only considers an elastic stress distribution, which does not 
capture the post-yield mechanics of failure. Other work done on breakout assumes a friction based failure criterion such as Mohr-Coulomb (Vernik \& Zoback 1992; Zoback et al. 1985). In brittle rock, Diederichs (2003) and Martin (1997) have shown initiation of failure is not confinement dependant and, therefore, is not initially governed by a substantial frictional component.

\subsubsection{Breakout in brittle rock}

Much work has been done to characterise breakout mechanisms in the hopes of improving the ability to estimate in situ stress. It has largely been shown that the progression of breakout is dependent on porosity, mineralogy, grain size and the composition of the inter-granular matrix (Haimson 2006). In a low porosity, crystalline rock, failure initiates back from the borehole wall along trans-granular cracks that are oriented sub-parallel to $\sigma_{H}$, opening perpendicular to the $\sigma_{h}$ axis. Similar to what is observed in uniaxial compression tests, these micro-cracks are extensional with no apparent shear offset. After a critical stress is achieved, the cracks begin to coalesce to form coherent layers parallel to the borehole wall. These begin to fail into the borehole until a notch is formed, where the geometry of breakout reaches equilibrium with the in situ stress (Haimson 2006). This dilatant failure can be roughly approximated as spalling failure, which is observed in larger excavations at depth (Diederichs 2003; Martin 1997).

\section{Case study}

\subsection{Victoria project, Sudbury Basin}

KGHM's Victoria project is found along the western margin of the Sudbury Basin's South Range. This $\mathrm{Ni}-\mathrm{Cu}$-PGE brownfield development is associated with mineralisation in the Worthington Offset Dyke, which is proximal to the regional scale Creighton Fault Structure.

The footwall assemblage at the location of the proposed shaft is comprised of interbedded metavolcanics and metasediments (MTSDs) with occasional mafic intrusions (Quadra FNX Mining LTD. 2011). The structural trend of these units is east-southeast and steeply dipping $\left(75^{\circ}\right.$ to $\left.80^{\circ}\right)$ to the south-southwest. Proximal to the offset dyke is the interpreted location of closure and fold hinge of the synformal Sudbury Basin. As a result, there are zones of NE/SW shearing and some variability in structural fabric orientation. Where the offset intersects the Creighton Fault, there is a dextral shift of the unit to the west. Potentially economic mineralisation and the proposed location of both the ventilation and production shafts are south of this fault structure.

\subsubsection{Lithology description}

Along the vertical pilot hole, there are five lithologies that incur regular breakout. These include the MTSD, metabasalt (MTBS), rhyolite (RHY), and metagabbro (MTGB/MXGB) of the footwall assemblage, with later stage quartz-diabase (QDIA) intrusions. From previous laboratory testing and core logging, each unit has been summarised in Table 1.

Table 1 Summary of testing results for each major lithology along the axis of the shaft pilot hole. Testing has been reported to conform with ISRM standards (MDEng 2015)

\begin{tabular}{llll}
\hline Lithology & UCS $(\mathrm{MPa})$ & $\boldsymbol{E}_{\boldsymbol{i}}(\mathrm{GPa})$ & Foliation description \\
\hline MTSD & 104.0 & 38.0 & Moderate \\
\hline MTBS & 115.7 & 48.5 & Moderate \\
\hline RHY & 145.4 & 50.7 & Intense \\
MTGB/MXGB & 80.2 & 31.4 & Faint \\
QDIA & 142.7 & 36.3 & None \\
\hline
\end{tabular}

UCS = unconfined compressive strength; $E_{i}=$ Young's modulus of intact rock 


\subsubsection{Stress influences}

Perhaps the largest overprinting stress influencer proximal to the Sudbury Basin is from the meteor impact that created it. Post-impact, it is thought to have caused a large degree of crustal thinning and mantle upwelling with reactivation of regional scale basement faults. Given the 'bowl-like' geometry of the basin (Figure 2), at any point around its perimeter, the stress tensor is defined by local structural features. This has been consistently demonstrated from structural fabric in the country rock surrounding the basin (Cowan et al. 1999; Santimano \& Riller 2012) and through in situ stress measurements at depth in mining settings (Snelling et al. 2012; Trifu \& Suorineni 2009; Walton et al. 2015b). Proximal to the Victoria project, the most prominent second order stress influencer is the Creighton Fault, which has a strike-slip component of movement. From previous measurements of the stress tensor near the fault shown by Cowan et al. (1999), the minor principal stress $\left(\sigma_{3}\right)$ is horizontal and parallel to the fault's strike. More distal to this in the Southern Range and throughout much of the Canadian Shield, $\sigma_{3}$ acts in the vertical direction with $\sigma_{1}=\sigma_{H}$ (Herget 1987).

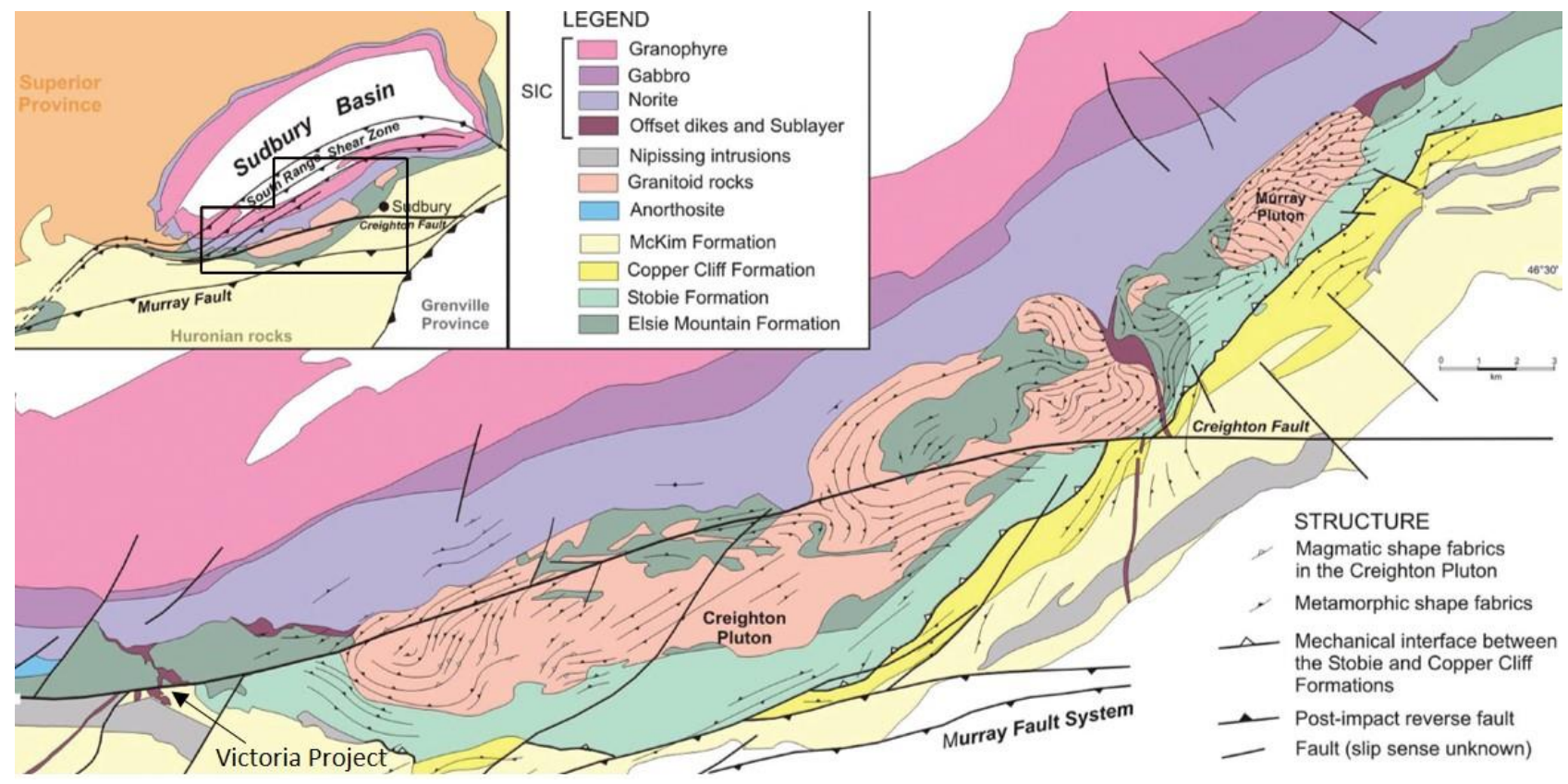

Figure 2 Structural map of the Southern Range of the Sudbury Igneous Complex. Inset in the top left corner is the entire Sudbury Basin with outline of the study location in the southwest. The Victoria project is highlighted in the bottom left corner (Modified after Riller 2005)

\subsection{Data acquisition}

\subsubsection{Acoustic televiewer}

ATV data has been gathered along the length of the $2 \mathrm{~km}$ pilot hole to assess the frequency and orientation of fractures and stress induced borehole breakout. For the purpose of this study, breakout characteristics were compiled for the interval $850-2,000 \mathrm{~m}$. Above this depth no appreciable stress-induced breakout was observed. Each breakout profile was characterised based on the average opening angle and breakout depth, normalised to the mean travel time of the undisturbed borehole (Figure 3). This process removes any uncertainty with converting from travel time to distance caused by the presence of drilling muds or water saturation in the borehole. Given that the borehole diameter also changed from HQ $(63.5 \mathrm{~mm})$ to NQ3 $(45 \mathrm{~mm})$ at 1,180 $\mathrm{m}$, the approach of normalising breakout depths allowed for each breakout to be assessed in parallel regardless of the borehole diameter (assuming size effects are negligible). 


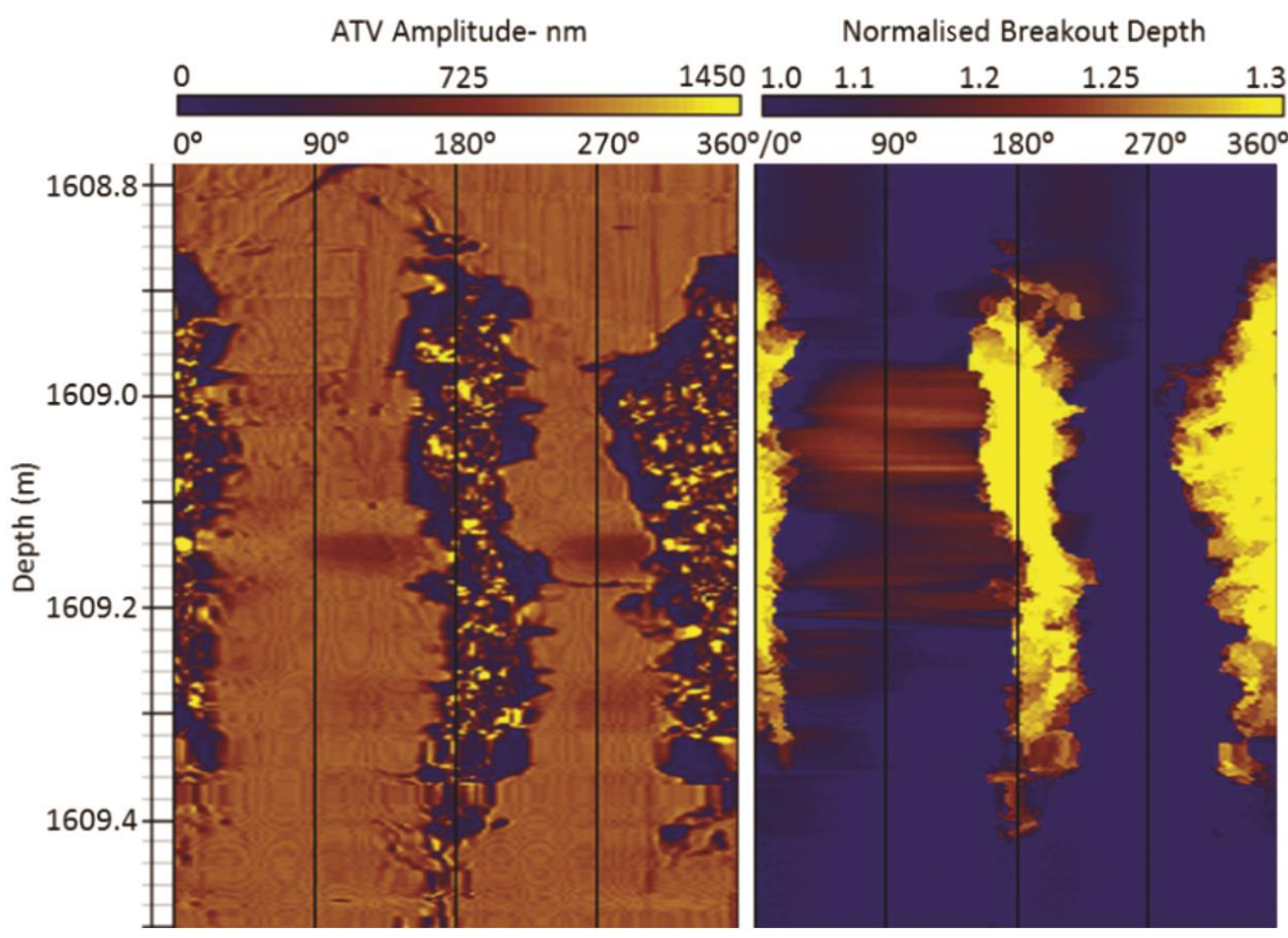

Figure 3 ATV image of breakout amplitude (left) with the post processed normalised breakout depth (right) at $1,609 \mathrm{~m}$. Breakout depth is plotted using a logarithmic scale

Breakout was only considered if there was greater than a $2.5 \%$ increase in travel time relative to the mean borehole travel time. Deviations smaller than this were not recorded as their scale approached that of the maximum rock grain size. Similar values for cut-off travel times were used by Walton et al. (2015a) based on their experiences in comparable brittle rock. A summary of the breakout selection criteria includes:

- Breakout that does not appear to be influenced by:

○ Major fault structures.

○ Sub-vertical jointing.

○ Contacts with quartz veins.

- Has greater than a $2.5 \%$ increase in ATV travel time from borehole wall to breakout apex.

- Has less than a $0.75^{\circ} / \mathrm{cm}$ deviation in breakout azimuth.

- Is not intersected along the length of breakout by a discontinuity.

\subsubsection{Breakout characteristics}

Upon applying the criteria previously described, 212 breakouts were selected for the back analysis of stress. The breakout results from the ATV survey can be seen in Figures 4 and 5, with the global average azimuth of breakout being approximately north-south, corresponding to a maximum horizontal principal stress in the east-west direction. Although stress variability in the Sudbury Basin is quite prominent, this result is consistent with other work done along the Southern Range (Snelling et al. 2012; Trifu \& Suorineni 2009; Walton et al. 2015a) and regionally in the Canadian Shield (Diederichs 1999; Herget 1987). 


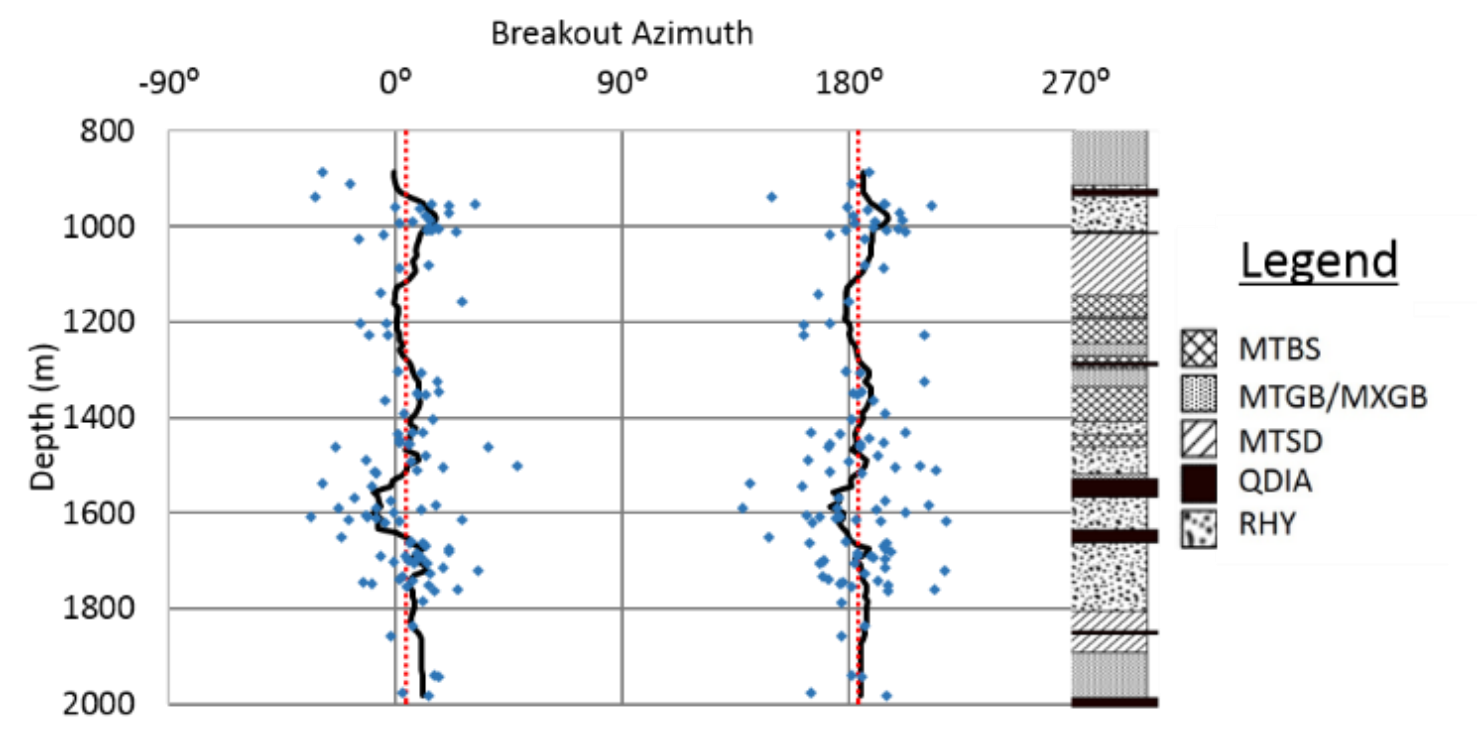

Figure 4 Orientation of measured breakouts from ATV survey. Individual measurement locations are shown as points with the mean breakout angle as the hashed line. An inverse square mean used for trend analysis (solid line)

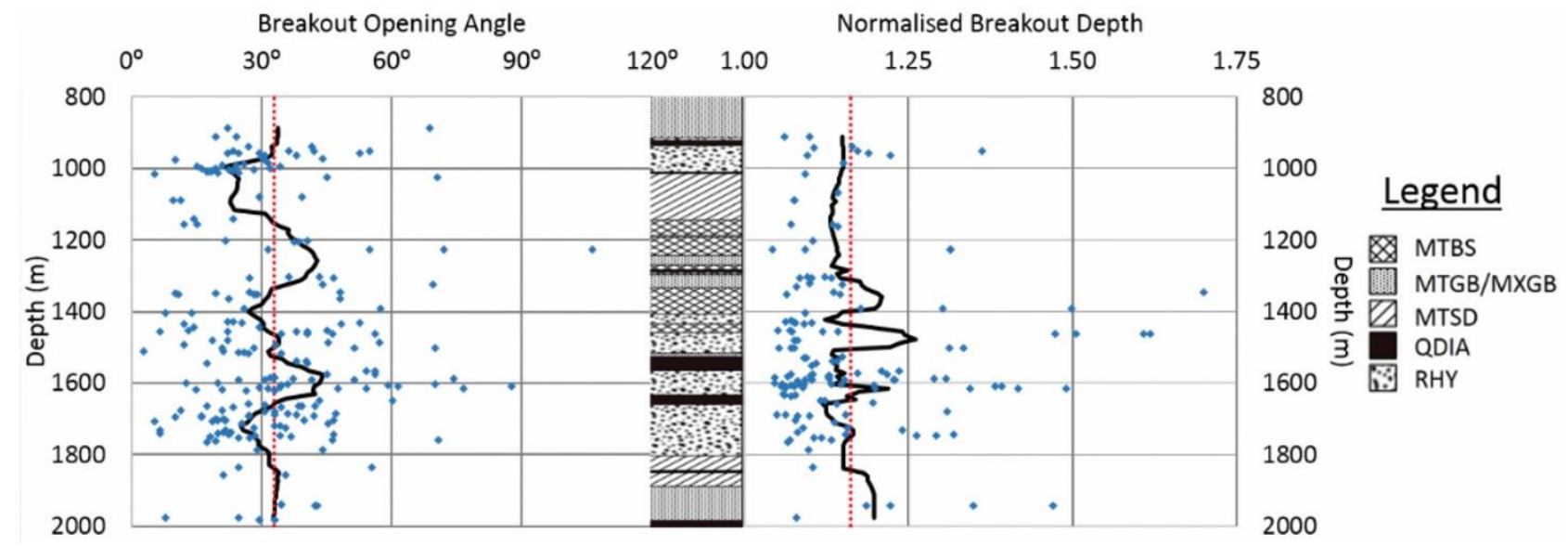

Figure 5 Opening angle (left) and normalised breakout depth (right) of measured breakouts from ATV survey. Individual measurement locations are shown as points with the mean breakout angle and breakout depth as the hashed line. An inverse square mean used for trend analysis (solid line)

As seen in Figure 4, there are minor rotations in stress observed at 1,000 m near the upper contact with the RHY and once again at $1,600 \mathrm{~m}$ within a sequence of RHY and QDIA. As shown by the distance weighted average (solid line), at 1,000 $\mathrm{m}$ the azimuth of breakout rotates $15^{\circ}$ in an eastward sense, while at 1,600 $\mathrm{m}$ it shows a $10^{\circ}$ deviation to the west. The rapid changes in breakout azimuth may suggest that the in-plane principal stress ratio is close to unity at these locations. This could allow small heterogeneities in the rock to play a greater role in influencing the geometry and orientation of breakout, particularly in the foliated units (RHY and MTSD).

Along the profile of the borehole, the shape of breakout (opening angle and breakout depth) are quite irregular. As shown in Figure 5, the mean breakout angle is $33^{\circ}$ with a breakout depth of 1.15 times the borehole radius. This relatively small-scale of breakout may further suggest that the average horizontal stress ratio is quite low, which supports the variability seen in breakout geometry and azimuth. Unlike the breakout azimuth, which is ideally only controlled by the far-field stress orientation, the shape of breakout is entirely dictated by stress magnitudes and mechanical rock properties (assuming a homogeneous/isotropic medium). 


\subsection{Breakout modelling}

When numerically modelling borehole breakout, the stress tensor can be iteratively changed until a result matching the observed breakout profile is achieved. In the context of estimating stress along the length of a borehole, this methodology proves to be time consuming as it requires multiple models to be run for each breakout occurrence. Walton et al. (2015a) also correctly observed that this method would be inefficient for reconciling what is observed in the field with the results produced during modelling. This is particularly true in cases where breakouts have an irregular profile and cannot be re-created through homogenous, continuum based modelling.

A proposed alternative to this is an approach creating a database of breakout profiles by adjusting the magnitude of stress around the borehole during subsequent model runs. For each model, an associated breakout profile can be logged in terms of opening angle and breakout depth. The observed breakouts from ATV data can then be compared to this set of models to estimate the changes in horizontal stress with depth.

\subsubsection{Modelling procedure}

Creation of the breakout database was completed using the continuum based finite-difference code FLAC3D-5.0. A radial mesh was applied extending outwards from the borehole axis with a radius of one unit used such that the observed breakout depths are normalised to the borehole size. A mesh density with the maximum side length of a zone less than $3.0 \%$ of the borehole radius was used proximal to the area of interest ( 0.5 radii from borehole centre). Work done by Walton and Diederichs (2015) has shown that this zonation size is dense enough to capture the brittle failure mechanics while avoiding any mesh dependency effects.

Between each consecutive model, the in-plane ratio of stress $\left(K_{x y}\right)$ was incremented at a rate of 0.1 , from 1.1 to 3.0. For each $K_{x y}$, the magnitude of stress was varied such that the ratio of maximum tangential wall stress to unconfined compressive strength $\left(R_{\sigma}\right)$, was between 1.05 and 2.0, incremented by 0.05 for each model. Breakout during each iteration was assessed based on opening angle and normalised breakout depth, to be used in creating the surfaces seen in Section 3.1. This was based on the occurrence of yielded zones in each model.

\subsubsection{Material properties}

Given the nature of brittle failure at the borehole scale, a cohesion-weakening-friction-strengthening (CWFS) constitutive model was used. This has been shown to most accurately replicate the extent of failure on a number of scales of excavation in hard rock (Diederichs 2003, 2007; Hajiabdolmajid et al. 2002; Martin 1997). It should be noted that for cohesion and friction angle, each reached fully mobilised values at identical magnitudes of plastic shear strain (0.2\%). Although authors such as Hajiabdolmajid et al. (2002) have shown that cohesion may reach a fully mobilised state earlier than friction in some brittle rocks, without adequate laboratory testing of the lithologies in question, it was decided to synchronise these rates.

Based on work by Diederichs $(2003,2007)$, it was shown that the initial friction angle $\left(\phi_{i}\right)$ is within the range of $10^{\circ}$ to $20^{\circ}$. For the breakout analysis it was, therefore, chosen to use a moderate value of $15^{\circ}$. Taking a representative UCS of $110 \mathrm{MPa}$, Equation (2) was used to determine an initial cohesion $\left(c_{i}\right)$ of $42 \mathrm{MPa}$.

$$
c_{i}=\frac{U \operatorname{CS} \times\left(1-\sin \phi_{i}\right)}{2 \cos \phi_{i}}
$$

The residual cohesion $\left(c_{r}\right)$ was set equal to $5 \%$ of the initial cohesion, as supported by the back analysis of excavation overbreak by Hajiabdolmajid et al. (2002) and Diederichs (2007). This same work also suggested an appropriate range of mobilised friction angle $\left(\phi_{m o b}\right)$ between $45^{\circ}$ and $65^{\circ}$. Based on the observations that a higher value is more representative of a very brittle and homogeneous rock type, $55^{\circ}$ was used throughout modelling of this faintly to intensely foliated rock.

The choice of dilation angle was made through experience of the authors. Walton et al. (2015b) has shown that from back analysis of pillar yield in Sudbury Granitoid, the dilation angle should be approximately 55\% of the mobilised friction angle. Given the fact that during the formation of breakout only a fraction of yielded 
material remains in place providing confinement, this may suggest that the dilatant component for this application should be less than what is indicated from that work. Due to this, a conservative value of dilation corresponding to $20 \%$ of the mobilised friction angle has been chosen.

Most of the parameters used in the modelling do not vary significantly in brittle rock with the exception of the initial cohesion, given its dependence on UCS. This further supports the decision to normalise breakout results by the BWS of each lithology due to the variability seen in laboratory testing data.

\section{In situ stress characterisation}

\subsection{Breakout database}

From the compilation of numerical modelling results, surfaces were fit relating the in-plane stress ratio and normalised tangential wall stress to the breakout geometry (Figure 6). For the surface fit of breakout opening angle (BOA) and normalised breakout depth (NBD), $R^{2}$ values of 93.5 and 98.4 were respectively achieved. The fits take the generalised form of:

$$
\begin{gathered}
B O A=e^{\left(a_{1}+b_{1} \cdot \frac{\ln \left(K_{x y}\right)}{K_{x y}}+\frac{c_{1}}{\ln \left(R_{\sigma}\right)}+\frac{d_{1}}{R_{\sigma}}\right)} \\
N B D=\frac{a_{2}+b_{2} \cdot \ln \left(K_{x y}\right)+c_{2} \cdot \ln \left(R_{\sigma}\right)}{1+d_{2} \cdot \ln \left(K_{x y}\right)+e_{2} \cdot\left(\ln \left(K_{x y}\right)^{2}\right)+f_{2} \cdot \ln \left(R_{\sigma}\right)}
\end{gathered}
$$

where:

$a_{i,}, b_{i} \ldots f_{\mathrm{i}}=\quad$ Fit constants dependant on material properties (Table 2 ).
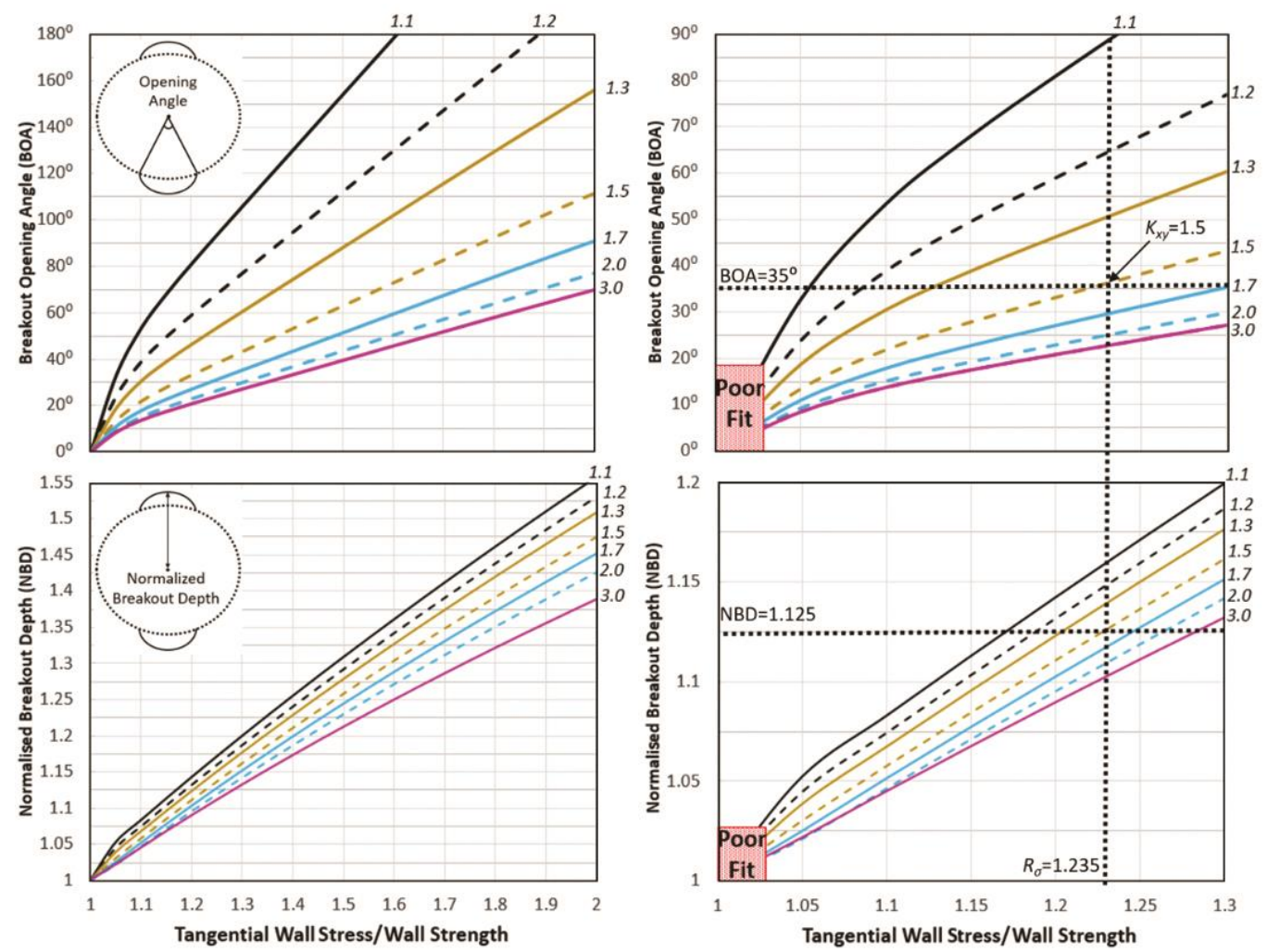

Figure 6 Plots from Equations (3) and (4), for use in graphical determination of stress. Each line defines an in-plane stress ratio shown along the border of each plot. The right figures are enlarged versions with demonstration of how to determine stress state using the hashed orthogonal lines 
Table 2 Fit constants used in Equations (3) and (4) to develop the graphical representation of breakout in Figure 6

\begin{tabular}{ccccccc}
\hline & $\mathbf{a}_{\mathbf{i}}$ & $\mathbf{b}_{\mathbf{i}}$ & $\mathbf{c}_{\mathbf{i}}$ & $\mathbf{d}_{\mathbf{i}}$ & $\mathbf{e}_{\mathbf{i}}$ & $\mathbf{f}_{\mathbf{i}}$ \\
\hline $\mathrm{i}=1$ & 7.690 & -4.860 & -0.035 & -3.220 & - & - \\
$\mathrm{i}=2$ & 1.030 & 0.280 & 0.380 & 0.370 & -0.055 & -0.270 \\
\hline
\end{tabular}

To determine the maximum principal stresses perpendicular to the borehole axis from in situ borehole breakout, Equations (3) and (4) can be solved for a corresponding in-plane principal stress ratio $\left(K_{x y}\right)$ and tangential wall stress ratio $\left(R_{\sigma}\right)$, which produces a matching BOA and NBD to the observed geometry. Alternatively, these ratios can be graphically determined as shown on the enlarged plots in Figure 6 . The procedure to do this is as follows:

- Draw a horizontal line at the breakout depth and opening angle (from in situ data).

- Locate the tangential wall stress ratio where both horizontal lines intersect the same curve.

- The value of the intersected curve provides the in-plane stress ratio.

Once the $K_{x y}$ and $R_{\sigma}$ pair have been solved for each breakout (either numerically or graphically) Equations (5) and (6) can be used to determine the magnitudes of principal stress at each location of breakout. For the presented example with a $K_{x y}$ of 1.5 and $R_{\sigma}$ of 1.235 , this produces a maximum in-plane principal stress $\left(\sigma_{H}\right)$ of $60.8 \mathrm{MPa}$ and minimum in-plane principal stress $\left(\sigma_{h}\right)$ of $40.5 \mathrm{MPa}$. It should be noted that in Equation (5) an effective BWS is used in lieu of UCS, which allows for the consideration of factors such as borehole fluid pressure and in situ rock strength (as discussed in Section 3.2).

$$
\begin{gathered}
\sigma_{h}=\frac{R_{\sigma} \times B W S}{3 K_{x y}-1} \\
\sigma_{H}=K_{x y} \times \sigma_{h}
\end{gathered}
$$

\subsection{Stress with depth}

From the summarised lithological information in Section 2.1.1 Table 1, the UCS was used to determine an effective BWS. From work done by Diederichs (2003) and Martin (1997) it has been shown that the in situ strength of rock is $70 \%$ to $80 \%$ of the UCS, which is broadly described as the crack-damage $\left(C_{d}\right)$ threshold. Due to the relative scale of the borehole to sample testing specimens and the dilatant nature of the rock (creating increased confinement throughout yield) an effective borehole strength of $90 \%$ UCS was used.

Given the depth-independent nature of the breakout database, a borehole column pressure $\left(P_{b}\right)$ was not explicitly applied during modelling. As a first pass analysis, the wall strength of the rock was increased by a value equal to the fluid pressure at that point (assuming the hole was filled to surface). As Walton et al. (2015a) showed, this is the minimum influence that water pressure would have on the borehole. Given that the material becomes increasingly frictional throughout progressive breakout, the fluid pressure may have a greater impact on wall strength than this.

The BWS used for the back calculation of stress took the following form:

$$
B W S=0.9 \times U C S+P_{b}
$$

Using the methodology described in Section 3.1, breakouts along the length of the pilot hole were used to evaluate the changes of horizontal stress as a function of depth. It should be noted that $11 \%$ of all breakout geometries that met the criteria described in Section 2.2.1 could not produce a result within the bounds of the model. These breakout profiles could, therefore, have been influenced by heterogeneities in the rock mass such as structure or stiffness contrasts (from quartz veining), which were not seen in the downhole survey. These outlying geometries could also generally demonstrate a drawback of using this method, as not all combinations of breakout shapes are captured throughout the iterative modelling process. 
From Figure 7, the interpreted magnitudes of principal stress appear to agree with the regional scale stress evaluation by Diederichs (1999). As depth increases, the breakout data begins to under-estimate the magnitude of stress (based on Diederichs 1999). This could represent a local decrease in stress or may further show the lack of consideration made regarding the influence of column pressure on progressive yielding of the rock (as previously discussed). This trend becomes more apparent with depth due to the greater confining pressure from the fluid and subsequent interaction with the frictional component of failure (Walton 2015a).

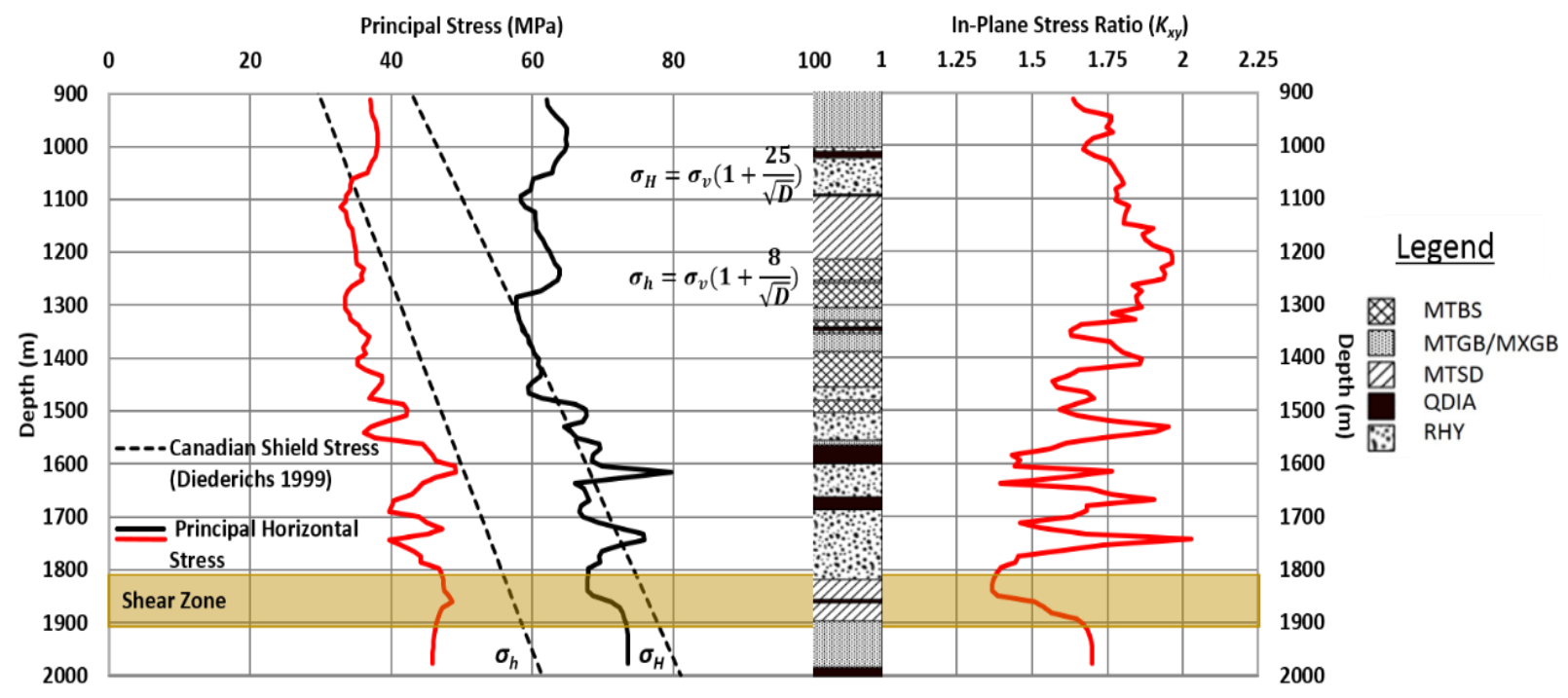

Figure 7 Major principal stress results from graphical fitting, with comparison to Canadian Shield stress assumptions (Diederichs 1999)

One noticeable increase in stress can be seen at $1,600 \mathrm{~m}$. This is reflected by a deviation of breakout azimuth by $10^{\circ}$ westwards (Figure 4) and a simultaneous increase in $B O A$ and NBD. A large decrease in $K_{x y}$ is seen just above the $100 \mathrm{~m}$ thick shear zone at 1,825 $\mathrm{m}$ depth. Although data resolution surrounding this zone is poor, this apparent drop in stress ratio could be indicative of an overall rotation of the stress tensor proximal to this structure.

\subsection{Effect of rock anisotropy}

Of the five lithologies that have been examined for breakout, the MTSDs and RHY demonstrate the most variability in breakout azimuth and opening angle. From the description of core, these two rock types also have a preferentially aligned foliation with most UCS tests failing along these planes of weakness (MDEng 2015). Much work has been done in sub-horizontally bedded shale to show the effects that systematic planes of weakness have on the occurrence of breakout (Meier et al. 2015; Zhang 2013). These authors have shown that the orientation of breakout will tend to rotate towards being aligned with the dip direction of the bedding, despite the orientation of the major principal stress. This trend becomes more apparent as the inclination of the planes of weakness increases. Despite the inherent mechanical differences between shale and the rock types in question for this study, the presence of micro-structure at high angles to the borehole should have similar effects on breakout geometry.

Modelling the effects of foliation was done using the finite-element software RS ${ }^{2}$ version 9.0 (Rocscience Inc 2016). To replicate brittle failure within the continuum, the damage initiation and spalling limit approach developed by Diederichs (2007) was used. This was done with the material properties discussed in Section 2.3.2. As seen in Figure 8, the foliation was modelled with regularly spaced elastic joints which were rotated by $5^{\circ}$ for every model run. The effects that the in-plane stress ratio has on breakout in anisotropic rock was also assessed by incrementing $K_{x y}$ between 1.25 and 2.0. It should be noted that a fully three dimensional analyses (borehole axis considered) may yield slightly varying results to this plane-strain model. Given the extensional nature of failure along the foliation, the evolution of stress in this axis may not be fully developed when only assuming these conditions. 

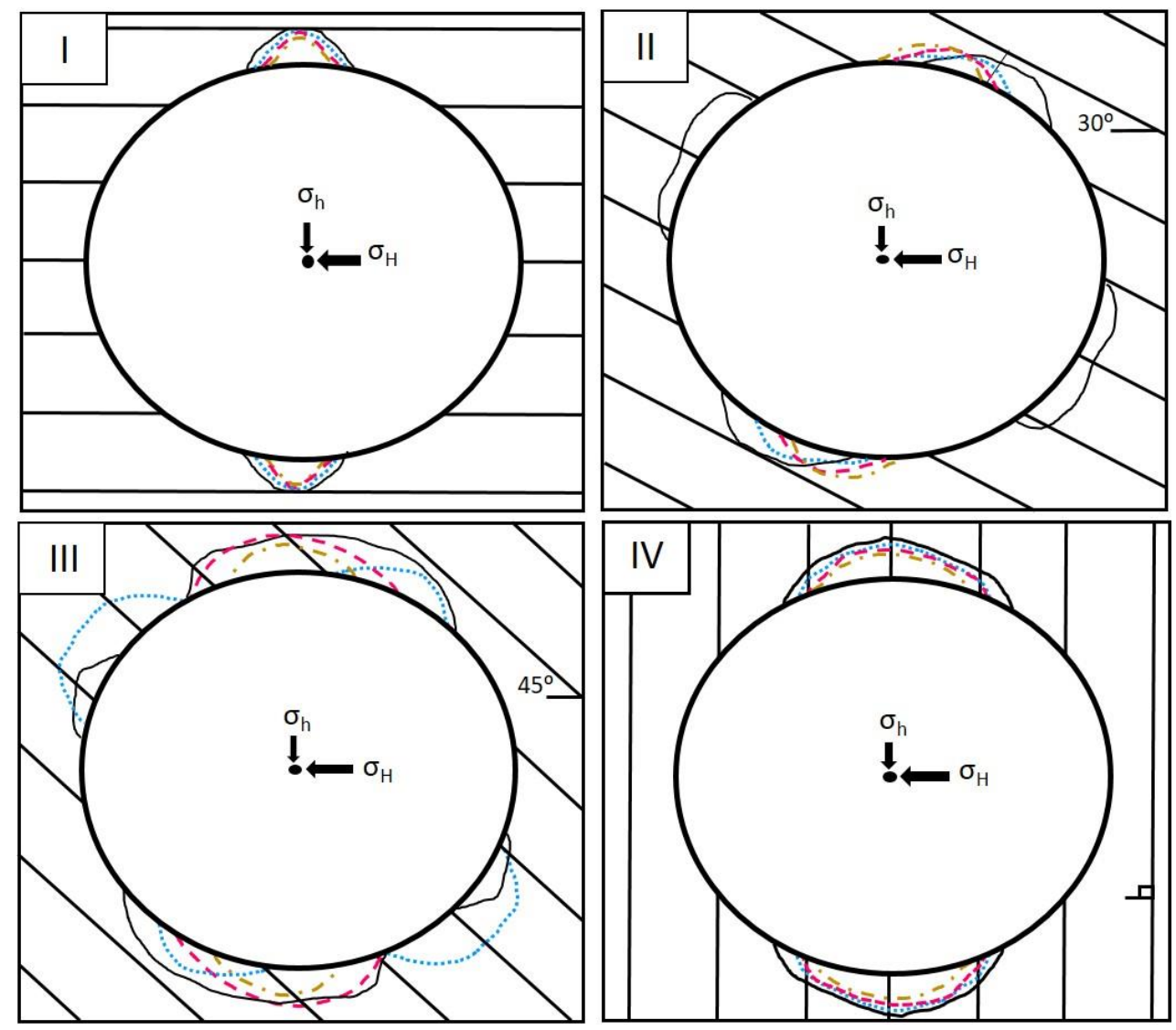

$-\mathrm{K}=1.25 \cdots \cdots \cdot \mathrm{K}=1.5--\mathrm{K}=1.75-\cdot-\mathrm{K}=2.0$

Figure 8 Modelling results of breakout characteristics for $K_{x y}$ ratios varying from 1.25-2.0. Failure types are described as: (I) $\theta=0^{\circ}$, initial breakout; (II) $\theta=30^{\circ}$, foliation perpendicular breakout; (III) $\theta=45^{\circ}$, mixed-mode breakout; and, (IV) $\theta=90^{\circ}$, foliation parallel breakout

As foliation rotates between $0-90^{\circ}$ relative to $\sigma_{H}$, there are three distinct types of breakout that are seen. The first occurs between $0-35^{\circ}$, where breakout is roughly perpendicular to the foliation. It can be seen in Figure 9 that for an increasing $K_{x y}$, the breakout azimuth tends to be dictated less by foliation orientation. This can be expected given the increasing magnitude of tangential wall stress, which governs breakout in a homogenous rock. This stress dependency in foliated rock is well exhibited in Figure 8, where breakout is less extensive for increasing stress ratios, and appears to rotate back towards the $\sigma_{h}$ axis.

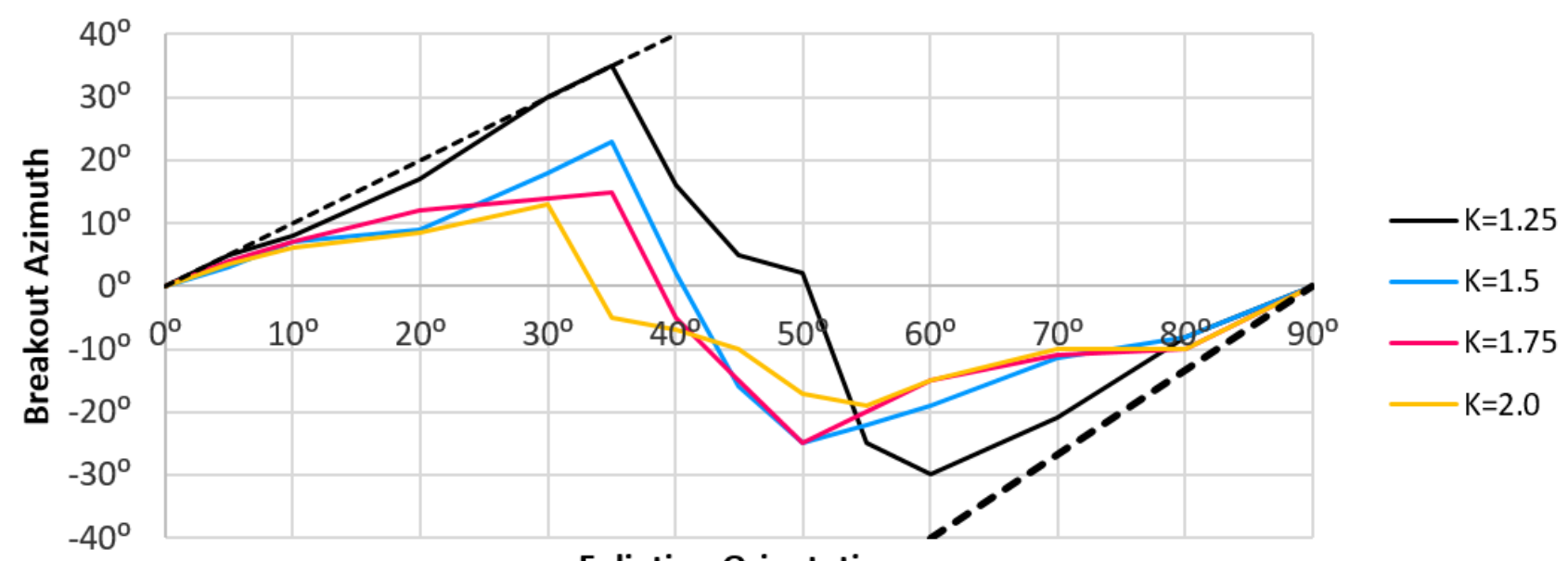

Foliation Orientation

Figure 9 Breakout azimuth at varying foliation orientations relative to the principal horizontal stress direction. Hatched trendlines show a 1:1 ratio between breakout azimuth and foliation angle 
As the discrepancy between foliation angle and the principal stress axis increases to $45^{\circ}$, breakout begins to occur both perpendicular and parallel to foliation between the individual planes of weakness. In low stress ratios, this sometimes creates four distinct breakouts around the circumference of the borehole (Figure 8-III). This results in large increases in the opening angle as the four breakouts begin to merge into a larger degree of borehole failure. From modelling, it was observed that this inter-plane failure was largely due to the exceedance of the rocks tensile strength, rather than the shear mode of failure observed in the 'foliation perpendicular' breakout.

Once the foliation orientation approaches $90^{\circ}$ to $\sigma_{H}$, the azimuth of breakout returns to being perpendicular with $\sigma_{H}$. It can be seen in Figure 8, that the opening angle does not return to the same size as when the foliation was parallel to the maximum principal stress. Given the inherent weakness of the joints relative to the intact rock, this result should be expected. It may, however, be somewhat dependant on the spacing of jointing and the elastic properties that were chosen.

In both the MTSDs and RHY, a joint set has been seen to form along the orientation of foliation. This has allowed for interpretation of foliation from oriented core logs of jointing, with the following trends (dip/dip direction):

- MTSD $-61 / 196^{\circ}\left(16^{\circ}\right.$ foliation orientation to $\left.\sigma_{H}\right)$.

- $\mathrm{RHY}-75 / 217^{\circ}\left(37^{\circ}\right.$ foliation orientation to $\left.\sigma_{H}\right)$.

Within the pilot hole there are two intersections of MTSDs at 1,050 $\mathrm{m}$ and just below $1,800 \mathrm{~m}$. Upon inspection of Figure 4 (Section 2.2.1.1), both occurrences show a minor rotation in stress on the order of $5-10^{\circ}$ in an eastward sense. With the average foliation rotated $16^{\circ}$ off the assumed $\sigma_{H}$, Figure 9 shows that a corresponding range of breakout azimuth is $6-15^{\circ}$ with a potential increase of opening angle by 1.25 times (Figure 10). This predicted rotation fits well with what is observed in the ATV data. In the case of the RHY (foliation rotated $37^{\circ}$ off the assumed $\sigma_{H}$ ), the foliation orientation is at the margin of the 'foliation perpendicular' and 'mixed-mode' breakout. At 1,000 m, the stress (from breakout orientation) shows an apparent rotation of $15^{\circ}$ to the east. With an average foliation orientation of $27^{\circ}$, this corresponds to a breakout azimuth of $10-30^{\circ}$ (Figure 9). A $10^{\circ}$ westward rotation of stress at 1,600 m occurred within the RHY. The geometry of breakout at this point also showed a sharp increase in breakout opening angle. This supports the theory that the RHY at this location may be prone to 'mixed-mode' breakout given the orientation of foliation. This failure type is also associated with the increase in opening angle from 2.0-2.5 times its original state. It is with these types of breakout that the in situ stress can be subject to notable overestimation and incorrect orientation if the presence of the micro-structure in the rock is not considered. This is evidenced in the stress estimations with depth where the largest variation of in-plane stress ratio and maximum principal stress occurs at $1,600 \mathrm{~m}$ and again at $1,700 \mathrm{~m}$ within the RHY.

One limitation of the current assessment of foliation is that the change in breakout depth from foliation angle cannot be assessed given the crudely chosen spacing of structure in the model. To reconcile this, calibration of the model using test data of a sample failing through foliation and one along foliation may be required. From work done in deep oil and gas reservoirs, it has shown that the wall strength at an anisotropy dip angle of $60^{\circ}$ had a minimum effective wall strength of $70 \%$ UCS at an angle to the major principal stress of $40^{\circ}$ (Duan \& Kwok 2015). This correlates well with the largest observed breakout angles occurring within a range of $40-50^{\circ}$ to $\sigma_{H}$ (Figure 10). It should be considered that this was work done on shale, which is associated with shear failure, rather than brittle extensional cracking. 


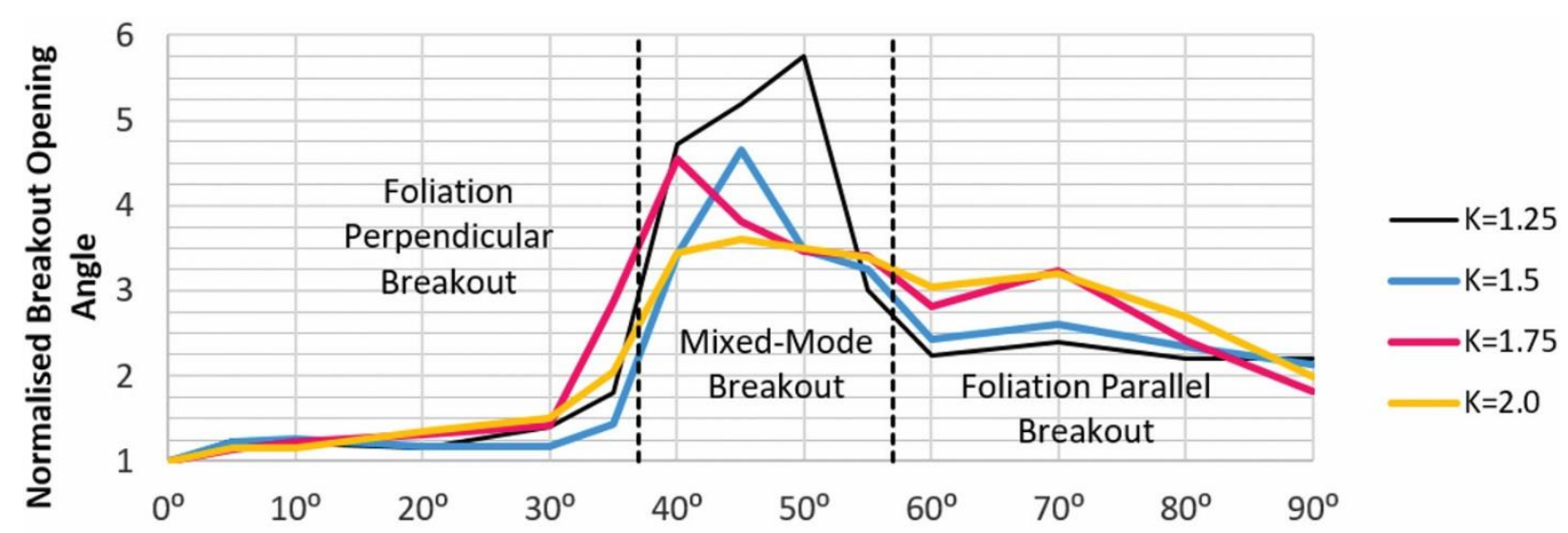

Foliation Orientation

Figure 10 Normalised breakout opening angle at varying foliation orientations relative to the principal horizontal stress direction. Breakout has been subdivided into three types: i) foliation perpendicular, ii) mixed-mode and iii) foliation parallel breakout. Each is shown in Figure 7

\section{$4 \quad$ Application to excavation design}

In general, the results from the back analysis of borehole breakout increases the resolution of stress with depth. The mechanics of brittle borehole breakout (described in Section 1.1.2) can be extrapolated to the mining excavation scale if the rock mass is homogeneous and structure-less. This would allow for prediction of the magnitude of overbreak using the methodology proposed in this paper. Given the volatile nature of orebody emplacement, the rock mass is rarely homogeneous and excavations are often irregularly shaped. In this case, caution must be taken in applying a suitable in situ rock strength that accounts for discontinuities or heterogeneities such as lithological contacts or veining.

Given the ability of borehole back analysis to incorporate strength variations between different units, this provides important insight into how excavation overbreak may change between each lithology. In the case of the pilot hole, RHY has shown to have a distinctly larger and more variable breakout shape over small distances. Whether this is due to stiffness contrasts with the surrounding layers or the presence of pervasive foliation, the same changes should be expected at the excavation scale. In heavily foliated mining environments such as Timmins and Kirkland Lake, Canada, similar 'foliation-perpendicular' excavation overbreak has been recorded (Mercier-Langevin \& Hadjigeorgiou 2011). As such, borehole failure in inherently anisotropic conditions should be an indication of expected failure mechanisms during mining development.

\section{Conclusion}

As a preliminary evaluation of stress, borehole breakout characterisation presents a strong alternative to other techniques such as estimation from regional databases or assumptions based on tectonic history. By creating a breakout database through numerical modelling, this has allowed for estimation of in-plane stress by comparing the observed breakout geometry from ATV surveys with the predicted modelling results. The presence of foliation during breakout acts to preferentially align breakout at a critical angle to the true in situ principal stress direction, causing an increase in the measured opening angle. This can be misinterpreted as apparent rotation of the far field stress tensor. If properly considered, the influence of foliation can be incorporated into the estimation of stress within anisotropic intervals. From this increased resolution of stress, a more thorough evaluation of key mine life controls such as excavation overbreak can occur with a greater degree of confidence.

\section{Acknowledgement}

The authors would like to recognise KGHM who have given continued access to data and the use of their core logging facility in Sudbury. The Natural Sciences and Engineering Research Council of Canada (NSERC) and Nuclear Waste Management Organization (NWMO) have also been instrumental in the funding of this research. 


\section{References}

Barton, CA, Zoback, MD \& Burns, KL 1988, 'In situ stress orientation and magnitude at the Fenton Geothermal Site, New Mexico, determined from wellbore breakouts', Geophysical Research Letters, vol. 15, no. 5, pp. 467-470.

Cowan, EJ, Riller, U \& Schwerdtner, WM 1999, 'Emplacement geometry of the Sudbury igneous complex: Structural examination of a proposed impact melt-sheet', in B Dressler \& V Sharpton (eds), Large Meteorite Impacts and Planetary Evolution II, Geological Society of America, Boulder, Colorado.

Diederichs, MS 1999, 'Instability of hard rockmasses: The role of tensile damage and relaxation', PhD thesis, The University of Waterloo, Waterloo, Ontario.

Diederichs, MS 2003, 'Rock fracture and collapse under low confinement conditions', Rock Mechanics and Rock Engineering, vol. 36, no. 5, pp. 339-381.

Diederichs, MS 2007, 'The 2003 geotechnical colloquium: Mechanistic interpretation and practical application of damage and spalling prediction criteria for deep tunnelling', Canadian Geotechnical Journal, vol. 44, no. 1, pp. 82-116.

Duan, K \& Kwok, CY 2015, 'Evolution of stress-induced borehole breakout in inherently anisotropic rock: Insights from discrete element modeling', Journal of Geophysical Research: Solid Earth, vol. 121, no. 1, pp. 2361-2381.

Haimson, B 2006, 'Micromechanisms of borehole instability leading to breakouts in rocks', International Journal of Rock Mechanics \& Mining Sciences, vol. 44, pp. 157-173.

Hajiabdolmajid, V, Kaiser, PK \& Martin, CD 2002, 'Modelling brittle failure of rock', International Journal of Rock Mechanics and Mining Sciences, vol. 39, no. 6, pp. 731-741.

Herget, G 1987, 'Technical note: Stress assumptions for underground excavations in the Canadian Shield', International Journal of Rock Mechanics and Mining Sciences, vol. 24, no. 1, pp. 95-97.

Kirsch, G 1898, 'Die Theorie der Elastizitat und die Bedurfnisse der Festigkeitslehre', Zantralblatt Verlin Deutscher Ingenieure, vol. 42, pp. 797-807.

Martin, CD 1997, 'Seventeenth Canadian geotechnical colloquium: The effect of cohesion loss and stress path on brittle rock strength', Canadian Geotechnical Journal, vol. 34, pp. 698-725.

Meier, T, Rybacki, E, Backers, T \& Dresen, G 2015,'Influence of bedding angle on borehole stability: A laboratory investigation of transverse isotropic oil shale', Rock Mechanics and Rock Engineering, vol. 48, no. 1, pp. 1535-1546.

Mercier-Langevin, F \& Hadjigeorgiou, J 2011, 'Towards a better understanding of squeezing potential in hard rock mines', Transactions of the Institution of Mining and Metallurgy, Section A: Mining Technology, vol. 120, no. 1, pp. 36-44.

MDEng (Mine Design Engineering) 2015, MDEng final report \#0308-R1412-D01 Victoria Project integrated engineering study, KGHM International, Sudbury, Ontario.

Quadra FNX Mining LTD. 2011, NI 43-101: Technical report on the Victoria Project Deposit, Sudbury, Ontario, Canada, Victoria Deposit, Sudbury.

Riller, U 2005, 'Structural Characteristics of the Sudbury impact structure, Canada: Impact-induced versus orogenic deformation-A review', Meteoritics \& Planetary Science, vol. 40, no. 11, pp. 1723-1740.

Rocscience, Inc. $2016 R S^{2}$, version 9.0, Rocscience, Inc., Toronto, Ontario, viewed 19 January 2017 , https://www.rocscience.com/rocscience/products/rs2

Santimano, T \& Riller, U 2012, 'Revisiting thrusting, reverse faulting and transpression in the southern Sudbury Basin, Ontario', Precambrian Research, vol. 200-203, pp. 74-81.

Snelling, PE, Laurent, G \& McKinnon, SD 2012, 'The role of geologic structure and stress in triggering remote seismicity in Creighton Mine, Sudbury, Canada', International Journal of Rock Mechanics \& Mining Sciences, vol. 58, pp. 166-179.

Trifu, Cl \& Suorineni, FT 2009, 'Use of microseismic monitoring for rockburst management at Vale Inco mines', in C Tang (ed.), Proceedings of the 7th International Symposium on Rockburst and Seismicity in Mines, Rinton Press, New York, pp. 1105-1114.

Vernik, L \& Zoback, MD 1992, 'Estimation of maximum horizontal principal stress magnitude from stress-induced well bore breakouts in the Cajon Pass scientific research borehole', Journal of Geophysical Research, vol. 97, no. B4, pp. 5109-5119.

Walton, G \& Diederichs, MS 2015, 'A mine shaft case study on the accurate prediction of yield and displacements in stressed ground using lab-derived material properties', Tunnel and Underground Space Technology, vol. 49, pp. 98-113.

Walton, G, Diederichs, MS, Hume, C \& Kalenchuk, K 2015a, 'Borehole breakout analysis to determine the in situ stress state in hard rock', Proceedings of the Forty-ninth US Rock Mechanics/Geomechanics Symposium, American Rock Mechanics Association, Alexandria, Virginia, pp. 287-304.

Walton, G, Diederichs, MS \& Punkkinen, A 2015b, 'The influence of constitutive model selection on predicted stresses and yield in deep mine pillars - A case study at the Creighton mine, Sudbury, Canada', Geomechanics and Tunnelling, vol. 8, no. 5, pp. 441-449.

Zhang, J 2013, 'Borehole stability analysis accounting for anisotropies in drilling to weak bedding planes', International Journal of Rock Mechanics \& Mining Sciences, vol. 60, pp. 160-170.

Zoback, ML 1992, 'First- and second-order patterns of stress in the lithosphere: The world stress map project', Journal of Geophysical Research, vol. 97, no. B8, pp. 703-728.

Zoback, MD, Moos, D \& Mastin, L 1985, 'Well bore breakouts and in situ stress', Journal of Geophysical Research, vol. 90, pp. 5523-5530. 